Revista Brasil. Bot., V.33, n.3, p.489-500, jul.-set. 2010

\title{
Coléteres foliares e calicinais de Temnadenia violacea (Apocynaceae, Apocynoideae): estrutura e distribuição ${ }^{1}$
}

\author{
FABIANO MACHADO MARTINS ${ }^{2,4}$, LUIZA SUMIKO KINOSHITA ${ }^{3} \mathrm{e}$ \\ MARILIA DE MORAES CASTRO 3
}

(recebido: 09 de dezembro de 2009; aceito: 12 de agosto de 2010)

\begin{abstract}
Foliar and calycine colleters of Temnadenia violacea (Apocynaceae, Apocynoideae): structure and distribution). The present work describes the origin, structure and position of the colleters on vegetative and floral apices of Temnadenia violacea (Vell.) Miers and confirms the presence of mucilage in the secretion produced by those structures. The number of foliar colleters ranges from 9 to 11 per primordium and from 18 to 22 per node; only one has an axilar origin, while the others originate along the margins. Concerning position, five of them are petiolar and the others are interpetiolar. There are two types of foliar colleters: standard and sessile, and they consist of a main body composed of a central core of elongated parenchyma cells surrounded by a secretory palisade epidermis and a thin cuticle. Tector trichomes and vascular tissue occur only on the distal marginal colleters. On the floral apices, the calycine colleters are formed at the base of the calyx, three of them opposite the sepals. All of the calycine colleters have a central core of elongated parenchyma cells, a secretory palisade epidermis, a thin cuticle, and are sessile. The calycine colleters are not vascularized and the laticifers are narrow. Mucilage was detected in the secretion of both foliar and calycine colleters.
\end{abstract}

Key words - anatomy, floral bud, mucilage, ontogeny, vegetative bud

RESUMO - (Coléteres foliares e calicinais de Temnadenia violacea (Apocynaceae, Apocynoideae): estrutura e distribuição). Este trabalho descreve a origem, estrutura e posição dos coléteres dos ápices vegetativos e florais de Temnadenia violacea (Vell.) Miers e comprova a presença de mucilagem na secreção produzida por estas estruturas. O número de coléteres foliares varia de 9 a 11 por primórdio e de 18 a 22 por nó; apenas um tem origem axilar, sendo os demais de origem marginal. Quanto à posição, cinco coléteres são peciolares e os demais interpeciolares. Os coléteres foliares são dos tipos standard e séssil, sendo constituídos por uma porção alongada, formada por um núcleo central de células parenquimáticas, revestido por epiderme secretora em paliçada uniestratificada e cutícula delgada. Tricomas tectores e tecido vascular ocorrem apenas nos coléteres marginais distais. No ápice floral, os coléteres calicinais têm origem na base do cálice, sendo três coléteres opostos a cada uma das lacínias. Todos os coléteres calicinais possuem um núcleo central de células parenquimáticas, epiderme secretora em paliçada uniestratificada, cutícula delgada e são sésseis; o eixo parenquimático destes coléteres é destituído de vascularização e os laticíferos observados são de pequeno calibre. A mucilagem foi detectada tanto na secreção dos coléteres foliares quanto dos calicinais.

Palavras-chave - anatomia, gema floral, gema vegetativa, mucilagem, ontogênese

\section{Introdução}

O termo coléter tem origem no grego kolla e foi introduzido por Hanstein (1848 apud Thomas 1991) referindo-se à secreção pegajosa produzida por esta estrutura. A secreção liberada pelo coléter pode ser composta apenas por mucilagem ou por uma mistura de

1. Parte da tese de doutorado do primeiro autor, Programa de PósGraduação em Biologia Vegetal, Universidade Estadual de Campinas, Campinas, SP, Brasil.

2. Universidade Federal do Recôncavo da Bahia, Centro de Ciências Agrárias, Ambientais e Biológicas, 44380-000 Cruz das Almas, BA, Brasil.

3. Universidade Estadual de Campinas, Instituto de Biologia, Departamento de Biologia Vegetal, Rua Monteiro Lobato, 255, 13083-862 Campinas, SP, Brasil.

4. Autor para correspondência: fmartins@ufrb.edu.br substâncias lipofilicas e hidrofílicas (Fahn 1979, 1990, Thomas 1991). Segundo Fahn (1979), essa estrutura pode estar presente em órgãos vegetativos e reprodutivos e tem a função de proteger e lubrificar os meristemas em início de desenvolvimento.

Os coléteres receberam diferentes denominações ao longo do tempo, dentre as quais podemos ressaltar: squamellae (Woodson \& Moore 1938, Rao \& Ganguli 1963, Ramayya \& Bahadur 1968), glandular shaggy hair (Solereder 1908, Metcalfe \& Chalk 1950 1979) e glândulas resiníferas (Subramanian et al. 1989). Além dessa diversidade de nomenclaturas, os coléteres também já foram confundidos com outras estruturas secretoras, tais como nectários extraflorais e glândulas resiníferas (Dave \& Patel 1975, Mohan \& Inamdar 1986). O termo coléter deve ser atribuído mediante a realização de testes que assegurem a presença da mucilagem no produto secretado. 
Na família Apocynaceae, os coléteres já foram observados em 65 gêneros, ocorrendo na forma de emergências ou glândulas persistentes em ápices vegetativos, folhas, brácteas, bractéolas e sépalas (Woodson \& Moore 1938, Rao \& Ganguli 1963, Ramayya \& Bahadur 1968, Fjell 1983, Dave et al. 1987, Thomas et al. 1989, Thomas \& Dave 1989a, b, c, 1990, 1991, Thomas 1991, Sennblad et al. 1998). As informações relativas a coléteres em espécies de Apocynaceae ocorrentes no Brasil ainda são escassas (Silva et al. 1975, Appezzato-da-Glória \& Estelita 2000, Rio 2001, 2006, Rio et al. 2002, 2005, Schwarz \& Furlan 2002, Demarco 2005, Simões et al. 2006). Apesar de vários trabalhos relatarem a ocorrência dos coléteres em Apocynaceae, essas estruturas podem estar ausentes em alguns gêneros (Woodson 1951, Sennblad et al. 1998, Endress \& Bruyns 2000, Demarco 2005). As espécies dessa família possuem folhas inteiras, com estípulas reduzidas ou ausentes (Judd et al. 2009); segundo a teoria estipular de Woodson \& Moore (1938), tanto os coléteres vegetativos quanto os calicinais pertencem à categoria de estípulas.

Este trabalho tem o propósito de validar a identificação das glândulas foliares e calicinais de Temnadenia violacea (Vell.) Miers como coléteres; descrever a estrutura, a distribuição e avaliar o potencial uso destas glândulas para taxonomia da tribo Echiteae G.Don.

\section{Material e métodos}

O material de estudo foi coletado em quatro áreas de cerrado do estado de São Paulo: Reserva Biológica e Estação Experimental de Moji Guaçu, Estação Ecológica e Experimental de Itirapina, Horto Botânico de Bauru e Laboratório Nacional de Luz Síncrotron em Campinas. Material testemunha proveniente de cinco indivíduos foi identificado pela Dra. Luiza S. Kinoshita e incorporado ao Herbário UEC: BRASIL. SÃo PAULO: Itirapina, 23-III-2003, F. Martins s.n. (UEC 147875); BRASIL. São PAULO: Itirapina, 23-III-2003, F. Martins s.n. (UEC 147874); BRASIL. SÃO Paulo: Moji Guaçu, 17-IV-2003, F. Martins s.n. (UEC 147873); BRASIL. São Paulo: Campinas, 25-IV-2003, F. Martins s.n. (UEC 147871); BRASIL. São PAULO: BAURU, 26-VI-2003, F. Martins s.n. (UEC 147872).

Ramos vegetativos com ápices caulinares, primórdios foliares, folhas e inflorescências portadoras de botões florais em diferentes estádios de desenvolvimento e flores em antese foram coletados. As amostras foram fixadas em FAA (formalina, ácido acético, álcool etílico 50\%, 1:1:18 $\mathrm{v} / \mathrm{v}$ ) por 24 horas (Johansen 1940) e FNT (formalina neutra tamponada; tampão fosfato, formalina, $9: 1 \mathrm{v} / \mathrm{v}$ ) por 48 horas (Lillie 1965). Todo o material foi submetido a vácuo em dessecador durante o processo de fixação e depois transferido para álcool etílico $70 \%$.

As peças foram isoladas e transferidas para álcool butílico terciário $70 \%$, onde permaneceram por aproximadamente sete dias, desidratadas em série butílica (Johansen 1940) e incluídas em parafina histológica. Seç̧ões seriadas transversais e longitudinais com espessura de aproximadamente $10 \mu \mathrm{m}$ foram obtidas em micrótomo rotativo.

Para o estudo estrutural, as secções foram coradas com safranina alcoólica 1,5\% e azul de astra aquoso 1\% (Gerlach 1969) e as lâminas permanentes montadas em resina sintética. Para evidenciar a presença de polissacarídeos na secreção, secções de material fixado em FAA foram tratadas com vermelho de rutênio (Gregory \& Baas 1989) e submetidas à reação PAS (Periodic-Acid-Schiff's reaction; McManus 1948). Os procedimentos adotados para a reação PAS são aplicados tanto em material fresco (L. Ascensão, comunicação pessoal) quanto fixado (Taboga \& Vilamaior 2007), com todas as secções histológicas pré-tratadas com tetrahidreto boreto de sódio $1 \%$, que bloqueia os aldeídos livres endógenos e fazendo com que apenas os grupos carbonilo formados durante a reação sejam corados. A omissão do tratamento pelo ácido periódico é efetuada em algumas secções histológicas para obtenção dos controles. As lâminas foram montadas em gelatina glicerinada.

As imagens digitais foram obtidas em microscópio Olympus BX51 acoplado a câmera digital Olympus E330. As escalas foram obtidas através da projeção de uma lâmina micrométrica nas mesmas condições ópticas das demais ilustrações. As medidas de comprimento dos coléteres foram realizadas em três ápices vegetativos e florais de cada indivíduo em câmara clara. A classificação dos coléteres esta de acordo com Lersten (1974).

\section{Resultados e discussão}

Coléteres foliares (figuras 1-14) - A descrição e as ilustrações da ontogênese dos coléteres vegetativos foram baseadas nas glândulas presentes no ápice caulinar vegetativo (figuras 1-10) e nos quatro nós visíveis subsequentes (figuras 11-14). Em cada nó, o número de coléteres foliares varia de 09 a 11 por primórdio e de 18 a 22 por nó. Apenas um coléter, o primeiro a se desenvolver, tem origem axilar e atinge até $400 \mu \mathrm{m}$ de comprimento (figuras 1-6). O número de coléteres marginais, de 09 a 10 por primórdio, varia entre indivíduos e em diferentes nós de um mesmo indivíduo. Estes coléteres possuem de 650 a $1.200 \mu \mathrm{m}$ de comprimento.

A variação no número de coléteres foliares marginais por primórdio em Temnadenia violacea também foi mencionada para algumas espécies da família. Em Allamanda cathartica L., Ramayya \& Bahadur (1968) registraram de 10 a 13 coléteres e Thomas \& Dave (1989a) observaram apenas 4 a 6 coléteres foliares para a mesma 

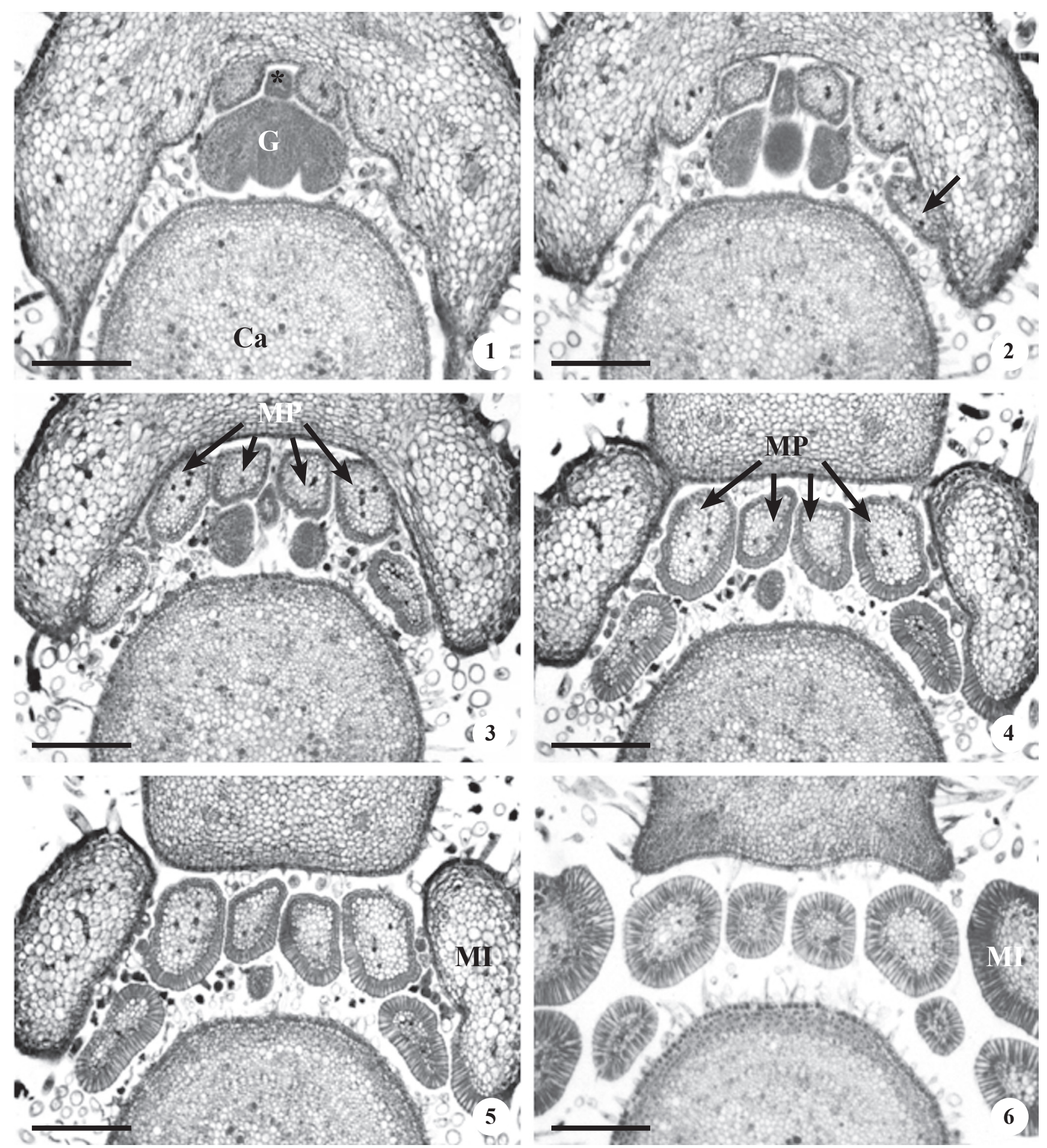

Figuras 1-6. Secções transversais do terceiro nó vegetativo de Temnadenia violacea. 1. Inicio da formação do coléter axilar (*). 2. Coléter formado na região interna da estípula (seta). 3-6. Coléteres marginais de posição intrapeciolar. 5-6. Coléteres marginais de posição interpeciolar. $(\mathrm{Ca}=$ caule; $\mathrm{G}=$ gema axilar; $\mathrm{MI}=$ coléter marginal de posição interpeciolar; $\mathrm{MP}=$ coléter marginal de posição intrapeciolar). Barra $=85 \mu \mathrm{m}$.

Figures 1-6. Transections of the third vegetative node of Temnadenia violacea. 1. Axillary colleter $(*)$ initiation. 2. Developing colleter on the internal region of the stipule (arrow). 3-5. Intrapeciolar marginal colleters. 6. Interpeciolar marginal colleters. $(\mathrm{Ca}=$ stem; $\mathrm{G}=$ axillary bud; $\mathrm{MI}=$ interpeciolar marginal colleter; $\mathrm{MP}=$ intrapeciolar marginal colleter $) . \mathrm{Bar}=85 \mu \mathrm{m}$. 
espécie. Um número diferente de coléteres peciolares foi encontrado em Thevetia peruviana (Pers.) K. Schum. por Fjell (1983) e Thomas (1991). Para Thomas (1991), o número dos coléteres de uma mesma espécie pode variar com a distribuição geográfica.

Os primeiros coléteres marginais a serem formados iniciam o desenvolvimento a partir da região interna do primórdio foliar, adquirem posição intercalar em relação ao coléter axilar e o último coléter marginal formado. Os últimos coléteres marginais a serem formados ficam mais distais e são os maiores (figuras 5-6). Quanto à posição, o coléter axilar e quatro dos coléteres marginais são peciolares; os demais, ocupam posição interpeciolar (figuras 1-6).

Todos os coléteres são constituídos por uma porção alongada, formada por um núcleo central de células parenquimáticas revestido por epiderme secretora em paliçada uniestratificada e cutícula delgada (figuras 710). O coléter axilar e os marginais distais possuem pedúnculo curto, formado por uma epiderme não secretora unisseriada com células de formato retangular, sendo identificados como do tipo standard (figura 7). Os coléteres marginais intercalares são sésseis.

O coléter do tipo standard observado no ápice vegetativo de $T$. violacea já foi registrado em pecíolos e margens foliares de outras espécies de Apocynaceae, tais como em Allamanda cathartica, Forsteronia australis Müll. Arg., F. glabrescens Müll. Arg., F. pubescens A. DC., F. thyrsoidea (Vell.) Müll. Arg., Mandevilla illustris (Vell.) Woodson, Mandevilla pohliana (Stadelm.) A.H. Gentry (= Mandevilla velutina (Mart. ex Stadelm.) Woodson) e Prestonia coalita (Vell.) Woodson (Thomas \& Dave 1989a, Appezzato-da-Glória \& Estelita 2000, Rio et al. 2002, 2005).

Nos coléteres marginais distais de $T$. violacea, a epiderme não é secretora apenas na região basal da face dorsal, onde os tricomas tectores unicelulares são observados; outra característica presente apenas nestes coléteres é a manutenção do tecido vascular (xilema e floema) na região central do coléter (figura 9). Tricomas tectores em coléteres foram registrados em Aganosma (Dave et al. 1987) e P. coalita (Rio et al. 2002), vascularização em Mandevilla illustris (Appezzato-daGlória \& Estelita 2000) e P. coalita (Rio et al. 2002). Thomas \& Dave (1991) consideraram que características como vascularização e presença de tricomas são um passo evolutivo entre os coléteres de Apocynaceae.

Os coléteres foliares intercalares de $P$. coalita (Rio et al. 2002) e os marginais distais de $T$. violacea apresentam características muito semelhantes, tais como tricomas tectores, epiderme não secretora na região basal da face dorsal, vascularização e pedúnculo curto. Este tipo coléter poderá constituir um caráter unificador nestes dois gêneros. De acordo com a circunscrição proposta por Endress et al. (2007), a tribo Echiteae está representada por 20 gêneros; destes, segundo Mabberley (2008), 11 ocorrem no Brasil. Há registro de presença de coléteres foliares e calicinais apenas para Parsonsia R. Br., Prestonia R. Br., Temnadenia Miers e Thenardia Kunth (Thomas 1991, Rio et al. 2002). A importância desta característica poderá ser avaliada com o estudo dos representantes de Echiteae.

A mucilagem é evidenciada no interior das células epidérmicas em paliçada dos coléteres e no meio extracelular no inicio do desenvolvimento dos primórdios foliares (figura 10) e em folhas jovens do primeiro ao quarto nó visível (figuras 11-14). A cutícula sempre permanece intacta após o período secretor dos coléteres de T. violacea; este mecanismo de liberação sem ruptura de cutícula também foi descrito em Plumeria (Mohan \& Inamdar 1986), Allamanda (Thomas \& Dave 1989a), Mandevilla (Appezzato-da-Glória \& Estelita 2000) e Blepharodon (Demarco 2005). Segundo Fahn (1990), a ruptura da cutícula é uma característica comum no mecanismo de liberação de secreção; entretanto, nos estudos de coléteres, esse mecanismo é mencionado apenas para os coléteres peciolares de Alstonia scholaris L. (Thomas \& Dave 1989b).

Mucilagem já foi detectada na secreção dos coléteres foliares em estádios iniciais de desenvolvimento de outras espécies de Apocynaceae (Appezzato-da-Glória \& Estelita 2000, Rio et al. 2002, Demarco 2005, Rio 2006). Segundo Thomas (1991), os coléteres começam a secretar antes da expansão foliar. A mucilagem está relacionada à função de lubrificar e proteger gemas na fase inicial do desenvolvimento dos primórdios (Fahn 1979).

Coléteres calicinais (figuras 15-22) - A descrição e as ilustrações dos coléteres calicinais foram realizadas a partir de botões florais com $4 \mathrm{~mm}$ e $30 \mathrm{~mm}$ de comprimento. No ápice floral, três coléteres sésseis têm origem na base do cálice e estão opostos cada uma das cinco lacínias (figura 15), razão pela qual são considerados calicinais; contrário ao observado nos coléteres foliares, o número de coléteres calicinais é sempre constante ( 15 coléteres) no cálice de todos os indivíduos estudados. Apenas o coléter central é séssil tripartido (seta, figuras 16-20) e o processo de ramificação em três partes desiguais se inicia no terço basal do coléter (figura 16). O comprimento destes coléteres varia entre $720 \mu \mathrm{m}$ e $840 \mu \mathrm{m}$ nos botões florais de $30 \mathrm{~mm}$. 

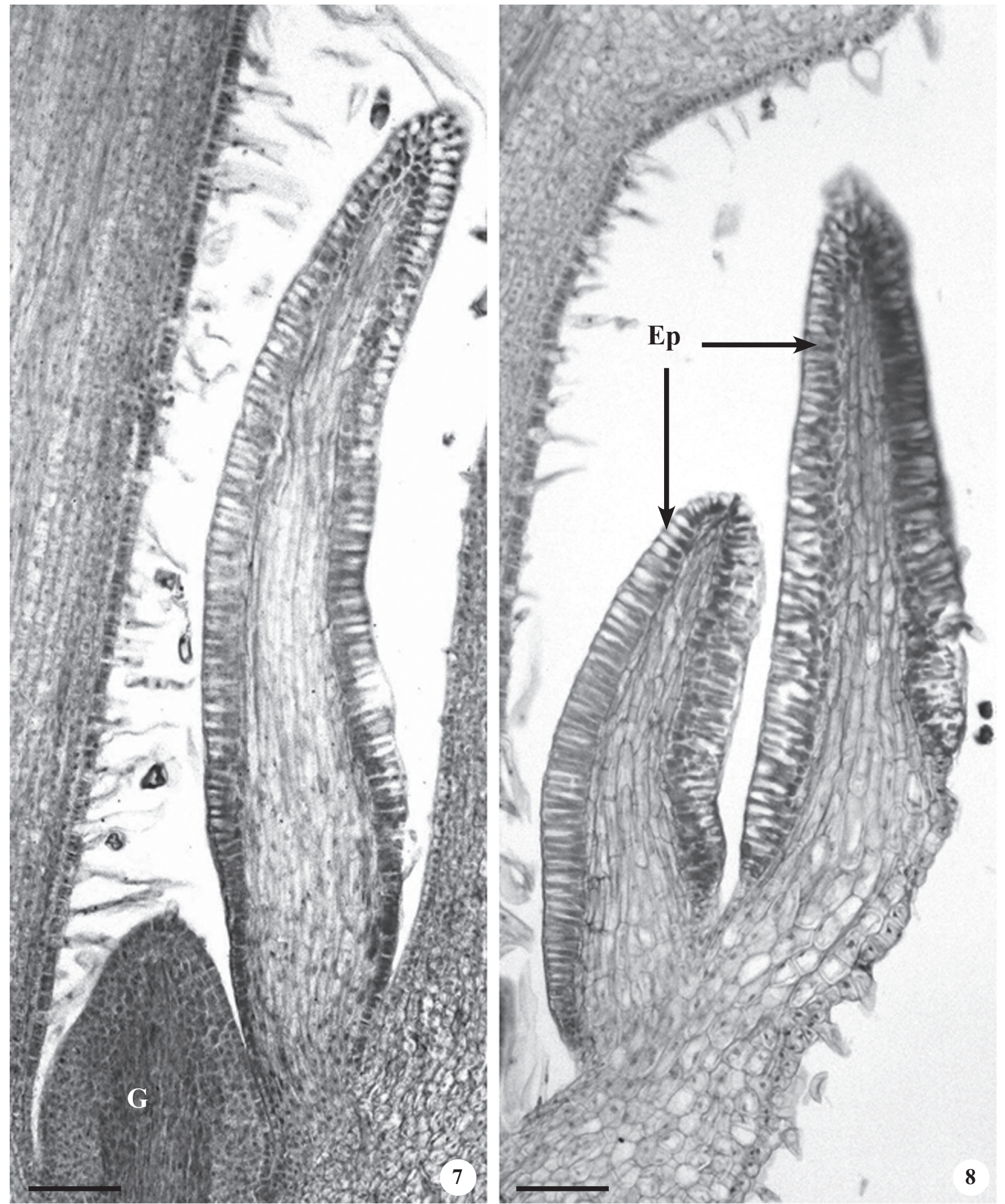

Figuras 7-8. Secções longitudinais de primórdio foliar de Temnadenia violacea. 7. Coléter axilar. 8. Coléter marginal. $(\mathrm{EP}=$ epiderme secretora; $\mathrm{G}=$ gema). Barra $=70 \mu \mathrm{m}$.

Figures 7-8. Longisections of the leaf primordia of Temnadenia violacea. 7. Axillary colleter. 8. Marginal colleter. (EP $=$ secretory epidermis; $\mathrm{G}=$ axillary bud). $\mathrm{Bar}=70 \mu \mathrm{m}$. 


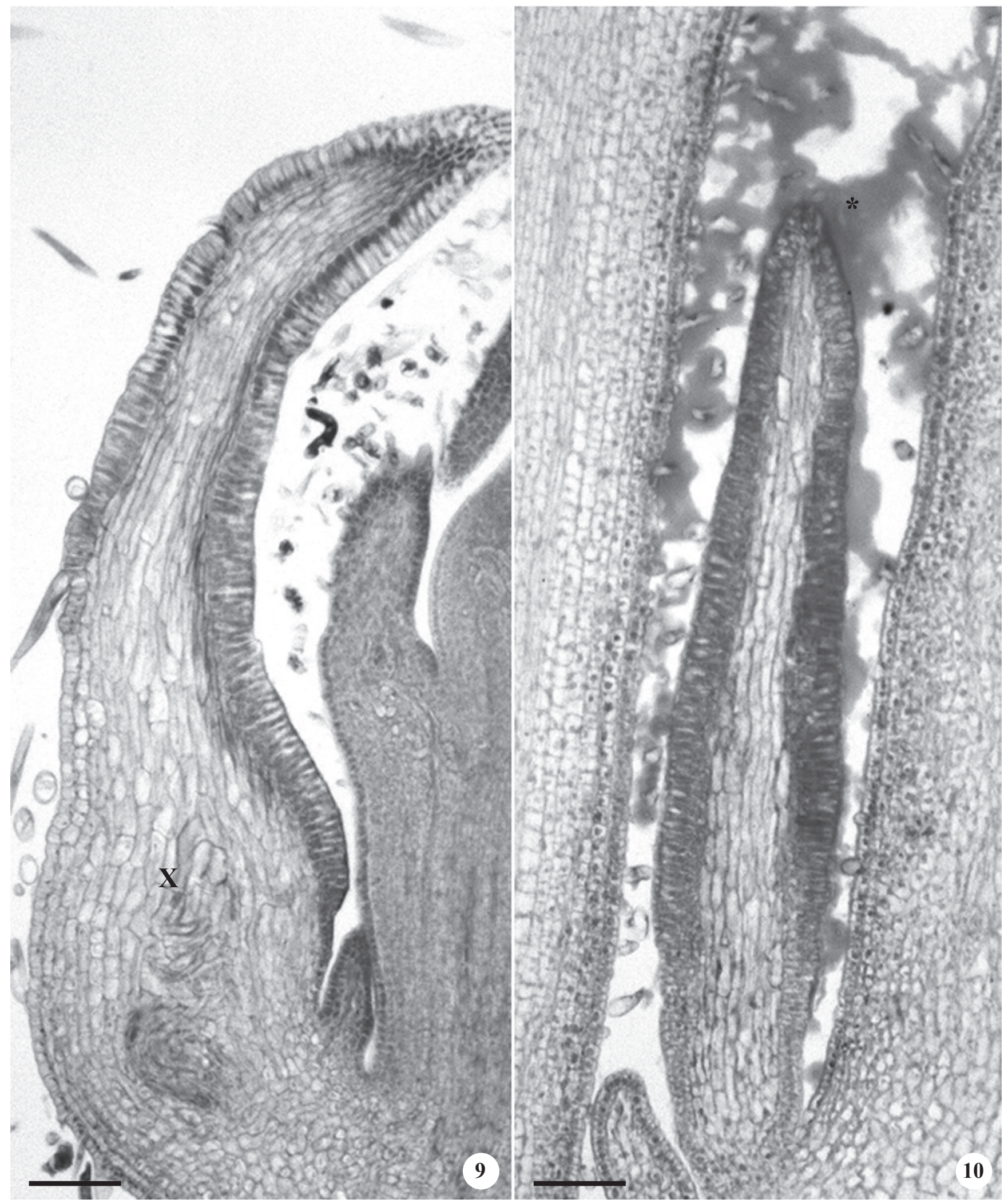

Figuras 9-10. Secções longitudinais de primórdio foliar de Temnadenia violacea. 9. Coléter marginal distal vascularizado. 10. Coléter axilar submetido à reação PAS. (* = secreção; $X=$ xilema). Barra $=70 \mu \mathrm{m}$.

Figures 9-10. Longisections of the leaf primordia of Temnadenia violacea. 9. Distal marginal colleter with evident vascularization. 10. Axillary colleter secretion stained pink with PAS reaction. $(*=$ secretion; $X=x y l e m)$. Bar $=70 \mu \mathrm{m}$. 

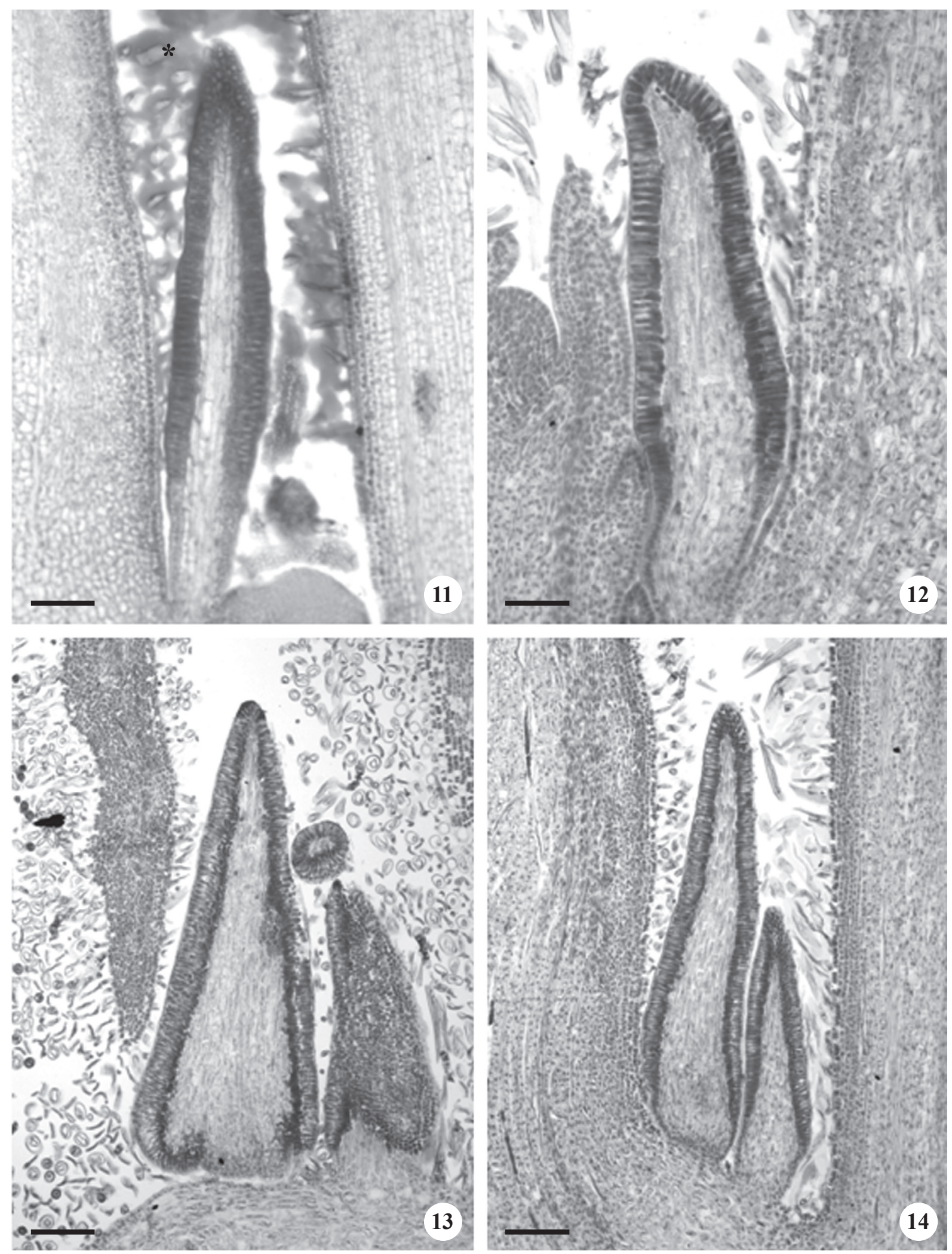

Figuras 11-14. Secções longitudinais do caule de Temnadenia violacea; coléteres submetidos à reação PAS. 11. Primeiro nó; secreção (*) no meio extracelular. 12. Segundo nó visível. 13. Terceiro nó visível. 14. Quarto nó visível. Barra $=70 \mu \mathrm{m}$.

Figures 11-14. Longisections of the stem of Temnadenia violacea; PAS reaction. 11. First node; secretion $(*)$ released by secretory epidermis. 12. Second node. 13. Third node. 14. Fourth node. Bar $=70 \mu \mathrm{m}$. 
Coléteres calicinais sésseis e sésseis partidos observados em $T$. violacea já foram observados em outras espécies de Apocynaceae, tais como Forsteronia australis, F. glabrescens, F. pubescens, P. coalita (Rio 2001, 2006), Mandevilla pycnantha (Steud. ex A. DC.) Woodson, Mandevilla tenuifolia (J. C. Mikan) Woodson e Mesechites mansoana (A. DC.) Woodson (Simões et al. 2006). Os termos bifurcados, partidos, ramificados e fimbriados podem ser considerados sinônimos.

A primeira classificação da tipologia de coléteres, proposta por Lersten (1974) para Rubiaceae e amplamente utilizada em outras famílias, não contempla vários tipos de coléteres, principalmente no que diz respeito à família Apocynaceae. Segundo Simões et al. (2006), a terminologia tradicionalmente utilizada para caracterizar e descrever os coléteres calicinais em Apocynaceae é um tanto confusa e ajustes são necessários para evitar interpretações equivocadas. Esses autores propõem tipologias que derivam do coléter standard, tendo a separação, a proliferação ou o alongamento das células do coléter como mecanismo fundamental de mudança; assim, ocorreria separação em partes distintas nos coléteres bifurcados, partidos, ramificados e fimbriados.

Em T. violacea, os coléteres são opostos aos lobos do cálice. Essa distribuição foi observada em espécies de outros gêneros de Apocynaceae, tais como em Cerbera, Mandevilla, Nerium, Prestonia e Tabernaemontana (Rao \& Ganguli 1963, Ramayya \& Bahadur 1968, Rio 2001, Simões et al. 2006). Além de coléteres calicinais opostos ao cálice, outras formas de distribuição ocorrem em Apocynaceae. Coléteres alternos ao cálice foram encontrados em Aganosma, Holarrhena, Mandevilla, Periploca, Secamone, Secondatia, Stephanostema, Strophanthus DC. (sin. Roupellia Wall. \& Hook. ex Benth.), Vallaris e Wrightia (Rao \& Ganguli 1963, Thomas et al. 1989, Sennblad et al. 1998, Simões et al. 2006) e coléteres contínuos distribuídos pela base do cálice formando uma franja foram evidenciados em Forsteronia, Mandevilla, Mascarenhasia, Mesechites, Nerium, Picralima, Thevetia e Trachelospermun (Sennblad et al. 1998, Rio 2006, Simões et al. 2006). Woodson \& Moore (1938) afirmaram que coléteres alternos representam uma condição basal, enquanto os opostos uma condição derivada.

Variação no número de coléteres calicinais foi descrita para Tabernaemontana divaricata (L.) R.Br. ex Roem. \& Schult. (Ramayya \& Bahadur 1968), Blepharodon bicuspidatum Fourn. (Demarco 2005), Forsteronia australis, F. glabrescens, F. pubescens e F. velloziana (A.DC.) Woodson (Rio 2006). Embora o número dos coléteres já tenha sido referido como caracter taxonômico relevante para espécies de Apocynaceae (Woodson \& Moore 1938), estudos quantitativos são necessários para verificar a relevância desse caráter para a taxonomia da família.

Assim como os coléteres foliares, os calicinais são constituídos por um núcleo central de células parenquimáticas revestido por epiderme em paliçada secretora uniestratificada e cutícula delgada (figura 21). A epiderme secretora em paliçada do coléter possui células com paredes delgadas, núcleo evidente e citoplasma denso. Na porção basal, a epiderme apresenta células menores, mas com as mesmas características de uma célula secretora (figura 21). O eixo parenquimático destes coléteres é destituído de vascularização.

A ausência de vascularização nos coléteres calicinais em espécies de Apocynaceae foi considerada uma característica predominante por Woodson \& Moore (1938); entretanto, coléteres calicinais vascularizados foram observados em Aganosma, Funtumia, Holarrhena, Nerium, Strophanthus, Vallaris e Wrightia (Woodson \& Moore 1938, Rao \& Ganguli 1963, Dave et al. 1987, Thomas \& Dave 1989c). Laticíferos de pequeno calibre estão presentes nos coléteres de alguns gêneros de Apocynaceae, tendo sido registrados em Allamanda, Mandevilla e Nerium, (Thomas \& Dave 1989a, 1991; Appezzato-da-Glória \& Estelita 1997, 2000).

A mucilagem é observada tanto no interior das células epidérmicas em paliçada dos coléteres de $T$. violacea quanto no meio extracelular (figura 21). Nos botões com menos de $4 \mathrm{~mm}$, os coléteres não apresentam atividade secretora evidente. Naqueles de botões com mais de $4 \mathrm{~mm}$, a secreção é encontrada tanto no interior das células epidérmicas em paliçada quanto no meio extracelular (figura 21). Em botões com mais de $30 \mathrm{~mm}$, a epiderme secretora dos coléteres tem aspecto senescente (figura 22). Semelhante ao relatado para os coléteres foliares, não há rompimento da cutícula na fase secretora, indicando que o exsudato seja liberado por microcanalículos da cutícula.

Os coléteres foliares de $T$. violacea diferem dos calicinais em origem, estrutura, número e posição. Os coléteres foliares são variáveis em número (entre 18 e 22 por nó), estrutura (tipos standard e séssil), posição (peciolar e interpeciolar) e origem (axilar e marginal). Os calicinais são sempre três, do tipo séssil, opostos a cada uma das lacínias e de origem axilar. Tricomas tectores, epiderme não secretora na região basal da face dorsal, vascularização e pedúnculo curto ocorrem apenas nos coléteres foliares marginais distais de T. violacea, que são muito semelhantes aos coléteres 

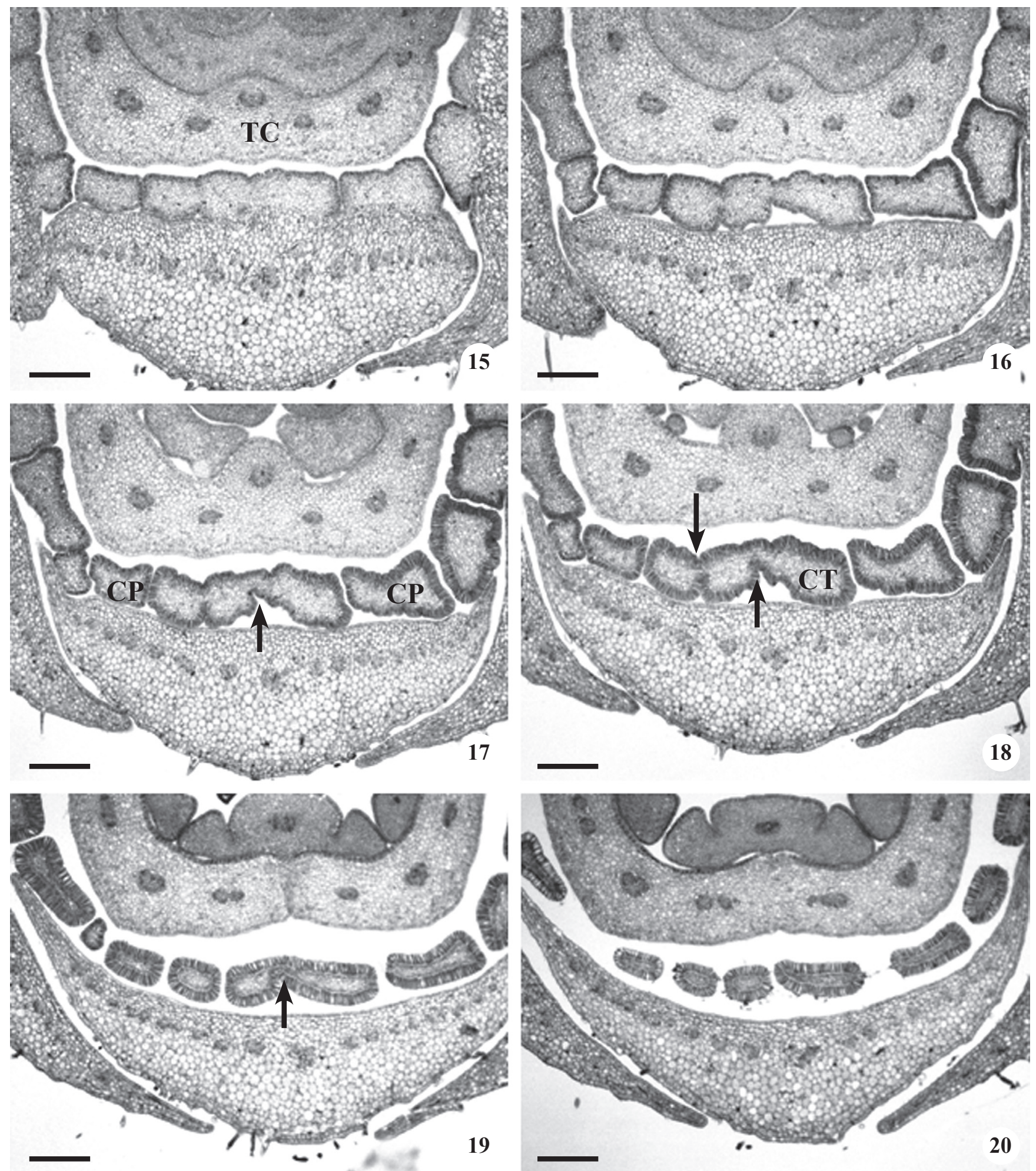

Figuras 15-20. Secções transversais do botão floral de Temnadenia violacea. 15. Base dos coléteres evidenciando origem e posição. 16-17. Inicio da ramificação do coléter tripartido. 18-19. Bifurcação do coléter tripartido (seta). 20. Coléteres opostos às sépalas. $(\mathrm{CP}=$ coléter padrão; $\mathrm{CT}=$ coléter tripartido; $\mathrm{TC}=$ tubo da corola $)$. Barra $=85 \mu \mathrm{m}$.

Figures 15-20. Transections of the floral bud of Temnadenia violacea. 15. Basal portion of colleters showing their origin and position. 16-17. Tripartite colleter initiation. 18-19. Sequence of bifurcation of a tripartite colleter (arrow). 20. Colleters opposite to sepals. $(\mathrm{CP}=$ standard colleter; $\mathrm{CT}=$ tripartite colleter; $\mathrm{TC}=$ corolla tube $)$. $\mathrm{Bar}=85 \mu \mathrm{m}$. 


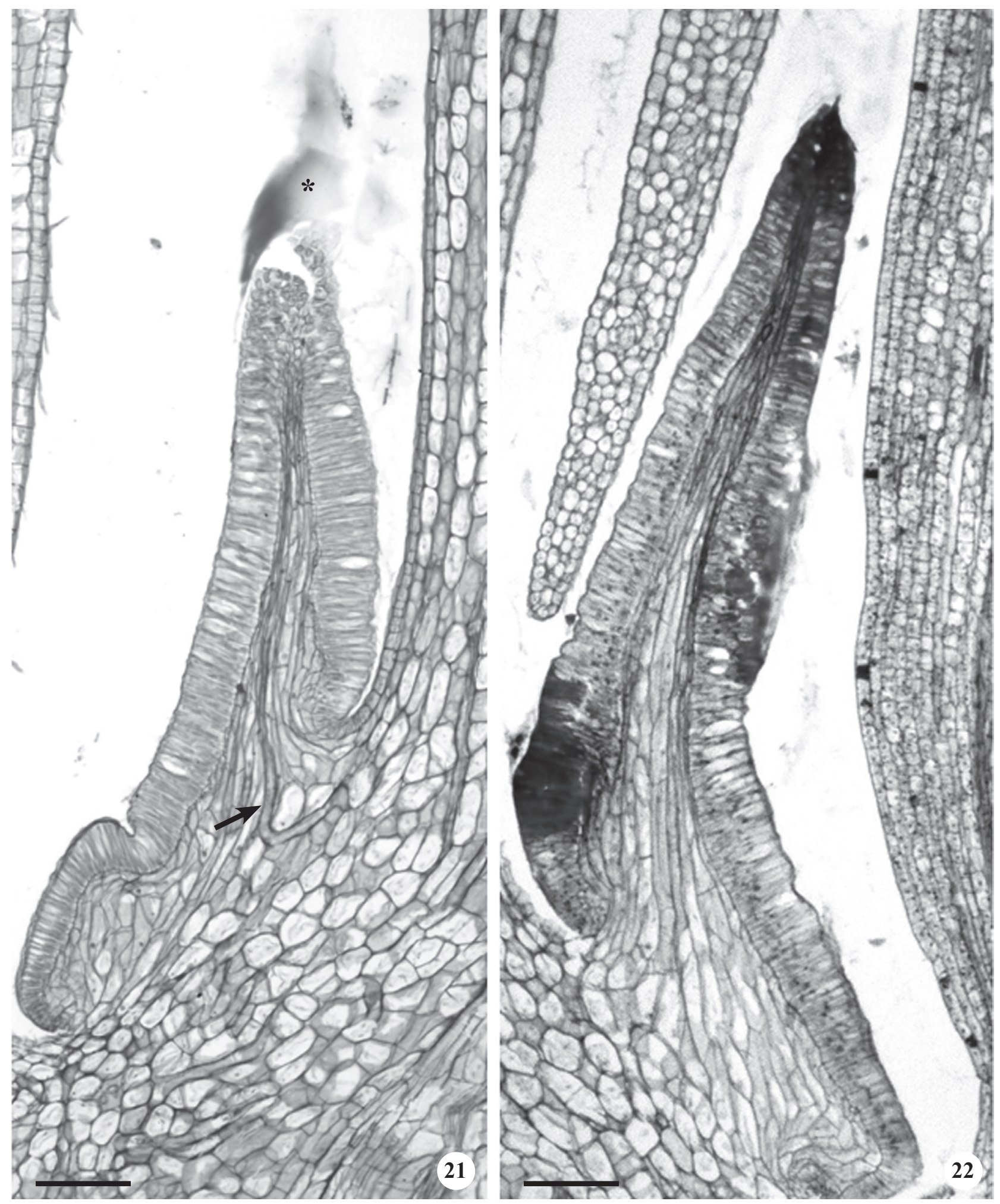

Figuras 21-22. Secções longitudinais de botões florais de Temnadenia violacea. 21. Secreção $\left({ }^{*}\right)$ no meio extracelular liberada por coléter séssil de botão de $c a .15 \mathrm{~mm}$ de comprimento. 22. Células secretoras em coléter senescente de botão de $c a$. $30 \mathrm{~mm}$. $($ Seta $=$ laticífero). Barra $=70 \mu \mathrm{m}$.

Figures 21-22. Longisections of the floral buds of Temnadenia violacea. 21. Secretion (*) released by secretory epidermis of sessile colleter of bud measuring $c a .15 \mathrm{~mm}$ long. 22. Secretory cells on senescent colleter of bud measuring $c a .30 \mathrm{~mm}$ long. $($ Arrow $=$ laticifer $)$. Bar $=70 \mu \mathrm{m}$. 
foliares intercalares de $P$. coalita (Rio et al. 2002). Este tipo de coléter poderá representar um caráter unificador nestes dois gêneros. A importância desta característica para Echiteae poderá ser avaliada com estudo dos demais representantes da tribo.

Agradecimentos - Os autores agradecem à Capes pela concessão da bolsa de doutorado ao primeiro autor e à Fapesp pelo auxílio à pesquisa (Biota/Fapesp proc. 00/12469-3).

\section{Referências bibliográficas}

APPEZZATO-DA-GLÓRIA, B. \& ESTELITA, M.E.M. 1997. Laticifer systems in Mandevilla illustris and $M$. velutina (Apocynaceae). Acta Societatis Botanicorum Poloniae 66:301-306.

APPEZZATO-DA-GLÓRIA, B. \& ESTELITA, M.E.M. 2000. Development, structure and distribution of colleters in Mandevilla illustris and M. velutina (Apocynaceae). Revista Brasileira de Botânica 23:113-120.

DAVE, Y., THOMAS, V. \& KURIACHEN, P.M. 1987. Structure and development of colleters in Aganosma caryophyllata G.Don. Pakistan Journal of Botany 19:243-248.

DAVE, Y. \& PATEL, N.D. 1975. A developmental study of extrafloral nectaries in slipper spurge (Pedilanthus tithymaloides, Euphorbiaceae). American Journal of Botany 62:808-812.

DEMARCO, D. 2005. Estruturas secretoras florais e coléteres foliares em espécies de cerrado de Aspidosperma Mart. e Blepharodon Decne (Apocynaceae s.l.). Tese de mestrado, Universidade Estadual de Campinas, Campinas.

ENDRESS, M.E. \& BRUYNS, P.V. 2000. A revised classification of the Apocynaceae s.l. The Botanical Review 66:1-56.

ENDRESS, M.E., LIEDE-SCHUMANN, S. \& MEVE, U. 2007. Advances in Apocynaceae: the enlightenment, an introdution. Annals of the Missouri Botanical Garden 94:259-267.

FAHN, A. 1979. Secretory tissues in plants. Academic Press, London.

FAHN, A. 1990. Plant anatomy. Pergamon Press, Oxford.

FJELL, I. 1983. Anatomy of the xeromorphic leaves of Allamanda neriifolia, Thevetia peruviana and Vinca minor (Apocynaceae). Nordic Journal of Botany 3: 383-392.

GERLACH, D. 1969. Botanische Mikrotechnik: Eine Einführung. Georg Thieme, Stuttgart.

GREGORY, M. \& BAAS, P. 1989. A survey of mucilage cells in vegetative organs of the dicotyledons. Israel Journal of Botany 38:125-174.

JOHANSEN, D.A. 1940. Plant microtechnique. McGraw-Hill, New York.
JUDD, W.S., CAMPBELL, C.S., KELLOGG, E.A., STEVENS, P.F. \& DONOGHUE, M.J. 2009. Sistemática vegetal: um enfoque filogenético. 3 a ed., Artmed, Porto Alegre.

LERSTEN, N.R. 1974. Morphology and distribution of colleters and crystals in relation to the taxonomy and bacterial leaf nodule symbiosis of Psychotria (Rubiaceae). American Journal of Botany 61:973-981.

LILLIE, R.D. 1965. Histopathologic technic and practical histochemistry. $3^{\text {rd }}$ ed., McGraw-Hill, New York.

MABBERLEY, D.J. 2008. Mabberley's plant-book: a portable dictionary of plants, their classification and uses. $3^{\text {rd }}$ ed., Cambridge University Press, Cambridge.

MCMANUS, J.F.A. 1948. Histological and histochemical uses of periodic acid. Stain Technology 23:99-108.

METCALFE, C.R. \& CHALK, L. 1950. Anatomy of the dicotyledons: leaves, stem and wood in relation to taxonomy with notes on economic uses. Clarendon Press, Oxford.

METCALFE, C.R. \& CHALK, L. 1979. Anatomy of the dicotyledons. Systematic anatomy of leaf and stem, with a brief history of the subject. $2^{\text {nd }}$ ed., Clarendon Press, Oxford.

MOHAN, J.S.S. \& INAMDAR, J.A. 1986. Ultrastructure and secretion of extrafloral nectaries of Plumeria rubra $\mathrm{L}$. Annals of Botany 57:389-401.

RAMAYYA, N. \& BAHADUR, B. 1968. Morphology of the "squamellae" in the light of their ontogeny. Current Science 37:520-522.

RAO, V.S. \& GANGULI, A. 1963. Studies in the floral anatomy of the Apocynaceae. Journal of the Indian Botanical Society 42:412-435.

RIO, M.C.S. DO 2001. Estudos taxonômicos e anatômicos do gênero Prestonia R. Br. nom. cons. (Apocynaceae). Tese de mestrado, Universidade Estadual de Campinas, Campinas.

RIO, M.C.S. DO 2006. Estudos anatômicos em espécies de Forsteronia G. Mey (Apocynaceae) de cerrado. Tese de doutorado, Universidade Estadual de Campinas, Campinas.

RIO, M.C.S. DO, CASTRO, M. DE M. \& KINOSHITA, L.S. 2002. Distribuição e caracterização anatômica dos coléteres foliares de Prestonia coliata (Vell.) Woodson (Apocynaceae). Revista Brasileira de Botânica 25: 339-349.

RIO, M.C.S. DO, KINOSHITA, L.S. \& CASTRO, M. DE M. 2005. Anatomia foliar como subsídio para a taxonomia de espécies de Forsteronia G. Mey. (Apocynaceae) dos cerrados paulistas. Revista Brasileira de Botânica 28:713-726.

SCHWARZ, E.A. \& FURLAN, A. 2002. Coléteres foliares de Oxypetalum R. Br. (Asclepiadoideae, Apocynaceae) - aspectos ultra-estruturais e anatômicos úteis à taxonomia das espécies do Paraná (Brasil). Acta Biológica Paranaense 31:79-97. 
SENNBLAD, B., ENDRESS, M.E. \& BREMER, B. 1998. Morphology and molecular data in phylogenetic fraternity: the tribe Wrightieae (Apocynaceae) revisited. American Journal of Botany 85:1143-1158.

SILVA, N.M.F., VALENTE, M. DA C., ALENCASTRO, F.M.M.R. DE, PEREIRA, J.F. \& SUCRE, B.D. 1975. Contribuição ao estudo das Asclepiadaceae brasileiras. Estudo taxonômico e anatômico de: Gonioanthela odorata (Decne.) Malme e Gonioanthela hilariana (Fourn.) Malme. Revista Brasileira de Biologia 35:745-756.

SIMÕES, A.O., CASTRO, M. DE M. \& KINOSHITA, L.S. 2006. Calycine colleters of seven species of Apocynaceae (Apocynoideae) from Brazil. Botanical Journal of the Linnean Society 152:387-398.

SOLEREDER, H. 1908. Systematic anatomy of the dicotyledons. Clarendon Press, Oxford.

SUBRAMANIAN, R.B., MURUGAN, V., MOHAN, J.S.S. \& INAMDAR, J.A. 1989. Optical microscopic studies on the structure and secretion of resin glands in some Apocynaceae. Proceedings of the Indian Academy of Sciences, Plant Science 99:423-429.

TABOGA, S.R. \& VILAMAIOR, P.S.L. 2007. Métodos de estudo da célula. Citoquímica. In A célula (H.F. Carvalho \& S.M. Recco-Pimentel, eds.). 2 ${ }^{\underline{a}}$ ed., Manole, Barueri, p.42-50.

THOMAS, V. 1991. Structural, functional and phylogenetic aspects of the colleter. Annals of Botany 68:287-305.
THOMAS, V. \& DAVE, Y. 1989a. Histochemistry and senescence of colleters of Allamanda cathartica $\mathrm{L}$. (Apocynaceae). Annals of Botany 64:201-203.

THOMAS, V. \& DAVE, Y. 1989b. Colleters of Alstonia scholaris L. - Apocynaceae. Indian Botanical Contactor 6:25-29.

THOMAS, V. \& DAVE, Y. 1989c. Structure, origin, development and senescence of colleters in Nerium indicum Mill. (N. odorum Soland. Apocynaceae). Korean Journal of Botany 32:163-172.

THOMAS, V. \& DAVE, Y. 1990. Mode of secretion in the colleters of Alstonia scholaris (Apocynaceae). Phyton 30:209-212.

THOMAS, V. \& DAVE, Y. 1991. Comparative and phylogenetic significance of the colleters in the family Apocynaceae. Feddes Repertorium 102:177-182.

THOMAS, V., DAVE, Y. \& MENON, A.R.S. 1989. Anatomy and hystochemistry of colleters in Roupellia grata (Apocynaceae). Nordic Journal of Botany 8:493-496.

WOODSON JR., R.E. 1951. Studies in the Apocynaceae. VIII. An interim revision of the genus Aspidosperma Mart. \& Zucc. Annals of the Missouri Botanical Garden 38:119-206.

WOODSON JR., R.E. \& MOORE, J.A. 1938. The vascular anatomy and comparative morphology of apocynaceous flowers. Bulletin of the Torrey Botanical Club 65: 135-165. 